\title{
Obesity and respiratory symptoms in primary school
}

\author{
S M SOMERVILLE, R J RONA, AND S CHINN \\ Department of Community Medicine, St Thomas' Hospital Medical School, London
}

SUMMARY The association of weight for height and triceps skinfold with seven respiratory symptoms has been examined using logistic regression analysis in 78005 to 11 year old children (6200 in England and 1600 in Scotland). The results support the view that overweight children have a greater liability to some respiratory symptoms than other children. After allowing for age, sex, and social factors, significant $(P<0.05)$ or borderline non-significant $(P<0 \cdot 1)$ positive associations were found between weight for height and the prevalence of bronchitis, 'chest ever wheezy', and 'colds usually going to the chest'. This suggests that some respiratory illness can be reduced by preventing children from becoming overweight. If this is correct, more than nutritional gains can be achieved by implementing an effective health education programme on obesity.

An increased incidence of respiratory infection has been observed in overweight infants aged less than 2 years. ${ }^{12}$ With the exception of studies of weight in asthmatic children, ${ }^{345}$ large community surveys of older children ${ }^{67}$ have not included an analysis of weight or fatness in relation to respiratory symptoms. Here the relation between respiratory symptoms and each of two measures of obesity, subcutaneous fatness (triceps skinfold) and weight adjusted for height (henceforth weight for height), is explored in the large sample of primary school children participating in the National Study of Health and Growth. ${ }^{8}$ The extent to which such a relation may be due to confounding factors is also considered.

\section{Methods}

The National Study of Health and Growth is of a mixed longitudinal design. ${ }^{8}$ Since 1972 , children aged 5 to 11 years in 22 areas of England and six areas of Scotland have been studied annually. Mothers are asked to complete a questionnaire about their children's health and family background. Data from 27 study areas in the 1977 survey were used in the analysis because questions about the number of smokers in the home were available that year.

Height, weight, and triceps skinfold of school children were measured by local nurses trained according to the methods of Tanner as described elsewhere. ${ }^{9}$ Weight for height and triceps skinfold are used in the analyses, expressed in standard deviation scores (SDS) ${ }^{10}{ }^{11}$ The SDS is calculated for each child as the difference between his or her measurement and the average measurement of a population of the same age, sex, and country divided by the standard deviation of the measurement for that population. Here overweight and underweight refer to the two extremes of the range for weight for height, and fat and lean for triceps skinfold. The studied respiratory symptoms are shown in Table 1.

Method of analysis. A logistic regression analysis was conducted for each respiratory symptom as a dichotomous dependent variable; the children being divided into two groups, those who had a positive response for the respiratory symptom and those who had a negative response. Children with a missing value were excluded. The analyses were conducted separately for weight for height and for triceps skinfold, each as a continuous independent variable. Many other independent variables were included in the analysis for each respiratory symptom because they had a possible association with respiratory symptoms. A sequence of linear models was fitted to the data to determine the extent to which the dependent variable was associated with each independent factor after adjustment for all other independent variables. The association with each obesity measure was also examined when adjustment was only made in the model for two of the independent variables, age and sex. This age-sex model was also 
Table 1 Questions on respiratory illness, number of children with a response to each question, and percentage of children with each symptom by sex and country

\begin{tabular}{|c|c|c|c|c|}
\hline \multirow[t]{3}{*}{ Respiratory symptom } & \multicolumn{2}{|l|}{ England } & \multicolumn{2}{|l|}{ Scotland } \\
\hline & \multirow{2}{*}{$\begin{array}{l}\text { Boys } \\
\text { No }(\%)\end{array}$} & \multirow{2}{*}{$\begin{array}{l}\text { Girls } \\
\text { No }(\%)\end{array}$} & \multirow{2}{*}{$\begin{array}{l}\text { Boys } \\
\text { No }(\%)\end{array}$} & \multirow{2}{*}{$\begin{array}{l}\text { Girls } \\
\text { No }(\%)\end{array}$} \\
\hline & & & & \\
\hline (1) Do colds usually go to his or her chest? & $3540(28 \cdot 0)$ & $3390(23 \cdot 0)$ & $1011(27 \cdot 6)$ & $949(22 \cdot 1)$ \\
\hline (2) Does his or her chest ever sound wheezy or whistling? & $3533(12 \cdot 7)$ & $3396(7 \cdot 8)$ & $1005(12 \cdot 2)$ & $956(7 \cdot 3)$ \\
\hline If yes, does he or she get this on most days or nights? & $3513(3 \cdot 1)$ & $3391(2 \cdot 1)$ & $1003(3.7)$ & $951(2 \cdot 7)$ \\
\hline $\begin{array}{l}\text { (3) Has he or she suffered from these illnesses in the last } 12 \text { months. } \\
\text { (a) Bronchitis }\end{array}$ & $3510(4.8)$ & $3370(3.1)$ & $097(4.4)$ & $048 \quad(3,4)$ \\
\hline (b) Asthma & $3500(3.9)$ & $3364(1.6)$ & $992(2 \cdot 3)$ & $942(1 \cdot 7)$ \\
\hline (4) Does he or she usually cough first thing in the morning? & $3521(3.7)$ & $3384(2 \cdot 6)$ & $998(3 \cdot 3)$ & $952(3 \cdot 6)$ \\
\hline (5) Does he or she usually cough during the day or at night? & $3515(6 \cdot 2)$ & $3372(5 \cdot 5)$ & $999(7 \cdot 9)$ & $948(6 \cdot 5)$ \\
\hline
\end{tabular}

fitted including a quadratic term for the obesity measure.

The independent variables included were: (a) the continuous variables, age in years, and birthweight in grammes; (b) number of siblings, treated as a quantitative variable; (c) the dichotomous variables, sex and "whether or not there was gas cooking in the home'; (d) father's social class subdivided into non-manual, skilled manual, semiskilled or unskilled manual, and the remainder (eg inadequately or not reported, fatherless families); (e) whether or not 'in current employment' or a 'one parent family', children with a missing value in each case being included as a separate group; (f) overcrowding defined as (number of adults plus number of children)/(number of bedrooms), three groups being included in the model (less than 1.5, 1.5 to less than $1.75,1.75$ or more); (g) the 'number of persons who smoked more than five cigarettes per day at home' split into 'none or not known', one, and two or more smokers; (h) and population density (persons per hectare) in the school catchment population-four ranges being used for England (less than 10, 10 to less than 20,20 to less than 30,30 or more), but only two for Scotland (less than 20,30 or more) where there was a smaller number of study areas, none of which had a density in the range 20 to 30 . Density figures were obtained from the 1971 census data for the ward or smallest appropriate catchment area of the school(s).

The population comprised 9923 children, of whom 9753 had a triceps skinfold and 9623 had a weight for height measurement. Information was missing for nine per cent of the 9923 children because parents refused to answer the questionnaire. In the logistic regression analyses children were excluded who had missing values except as mentioned above. The number of children with complete data ranged from 6146 to 6275 for England and from 1647 to 1675 for Scotland depending on the respiratory symptom used in the analysis. For
England the age-sex model was also fitted, including the children with missing values for some of the data to test whether the exclusions from the main analyses affected the results. The number of children in these analyses ranged from 6733 to 6876 .

\section{Results}

Table 1 presents the responses to the respiratory questions. There is little difference in the prevalence of respiratory symptoms between England and Scotland and boys had higher prevalence rates than girls.

Table 2 gives the results for the logistic regression analysis where adjustment was made for all the factors as described above. In general, the same pattern of associations was found when adjustment was only made in the model for age and sex, but the strength of a few of the associations increased-eg the borderline non-significant reached significance. In most of the analyses either triceps skinfold or weight for height, or both, were significantly positively associated with each of the three respiratory symptoms 'colds usually going to the chest', 'chest ever wheezy', and bronchitis-the fat and overweight children having the highest prevalence rates. In contrast, for 'cough first thing in the morning' and 'day or night cough' there was a negative association with triceps skinfold in England (which was highly significant in the latter case), the lean children having the raised prevalence rate.

When the age-sex model was fitted for England including the children with missing data, similar results were produced, although for bronchitis the association was reduced from $\mathrm{P}<0.05$ to $\mathrm{P}<0.1$ for triceps skinfold and from $\mathrm{P}<0.01$ to $\mathrm{P}<0.05$ for weight for height.

When boys and girls were considered separately for England the same patterns were found as for the total sample analyses. The conventional level of statistical significance with the smaller sample size, 
Table 2 Results of logistic regression analyses showing the association between respiratory symptoms and triceps skinfold and weight for height for the fully adjusted model. (Values= regression coefficient (standard error)).

\begin{tabular}{|c|c|c|c|c|c|c|c|c|}
\hline \multirow{3}{*}{$\begin{array}{l}\text { Respiratory symptom } \\
\text { Colds usually go to the chest }\end{array}$} & \multicolumn{4}{|l|}{ England } & \multicolumn{4}{|l|}{ Scotland } \\
\hline & \multicolumn{2}{|c|}{$\begin{array}{l}\text { Triceps skinfold SDS } \\
(N=6217-6275)\end{array}$} & \multicolumn{2}{|c|}{$\begin{array}{l}\text { Weight for height SDS } \\
(N=6146-6204)\end{array}$} & \multicolumn{2}{|c|}{$\begin{array}{l}\text { Triceps skinfold SDS } \\
(N=1651-1676)\end{array}$} & \multicolumn{2}{|c|}{$\begin{array}{l}\text { Weight for height SDS } \\
(N=1647-1672)\end{array}$} \\
\hline & $\$ 0 \cdot 057$ & $(0 \cdot 015)$ & $\$ 0 \cdot(073$ & $(0 \cdot 015)$ & $0 \cdot 012$ & $(0 \cdot 031)$ & ${ }^{*}(0 \cdot 053$ & $(0 \cdot 030)$ \\
\hline $\begin{array}{l}\text { Chest ever sound wheezy or } \\
\text { whistling }\end{array}$ & $0 \cdot 021$ & $(0 \cdot 022)$ & ${ }^{*}() \cdot(042$ & $(0 \cdot(21)$ & $0 \cdot 042$ & $(0 \cdot 045)$ & $\dagger 0 \cdot 105$ & $(0 \cdot(042)$ \\
\hline $\begin{array}{l}\text { Chest wheezy or whistling on } \\
\text { most days or nights } \\
\text { In the last } 12 \text { months had: }\end{array}$ & ${ }^{*}-0.072$ & $(0 \cdot 043)$ & $0 \cdot 016$ & $(0 \cdot 042)$ & $0 \cdot 002$ & $(0 \cdot 080)$ & $\dagger(0 \cdot 152$ & $(0 \cdot 075)$ \\
\hline Bronchitis attack(s) & $\dagger 0 \cdot 073$ & $(0 \cdot 033)$ & $\dagger 0 \cdot 081$ & $(0 \cdot 032)$ & $\dagger 0 \cdot 175$ & $(0 \cdot 068)$ & $\ddagger 0 \cdot 164$ & $(0 \cdot 061)$ \\
\hline Asthma attack(s) & $-0 \cdot 047$ & $(0 \cdot 040)$ & 0.004 & $(0 \cdot() 40)$ & $0 \cdot 111$ & $(0 \cdot 094)$ & $+0 \cdot 172$ & $(0 \cdot 085)$ \\
\hline $\begin{array}{l}\text { Usually coughs first thing } \\
\text { in the morning } \\
\text { Usually coughs during the }\end{array}$ & $-0 \cdot 058$ & $(0 \cdot 039)$ & $-0 \cdot 030$ & $(0 \cdot 039)$ & $-0 \cdot 089$ & $(0 \cdot(075)$ & $0 \cdot 051$ & $(0 \cdot 072)$ \\
\hline $\begin{array}{l}\text { Usually coughs during the } \\
\text { day or night }\end{array}$ & $\ddagger-0.080$ & $(0 \cdot 029)$ & $-0 \cdot(040$ & $(0 \cdot 029)$ & $-0 \cdot 023$ & $(0 \cdot 052)$ & $0 \cdot 042$ & $(0 \cdot(049)$ \\
\hline
\end{tabular}

$\mathrm{N}=$ The range of the number of children in the seven analyses.

${ }^{*} \mathrm{P}<0 \cdot 1 ;+\mathrm{P}<0 \cdot 05 ; \ddagger \mathrm{P}<0 \cdot 01 ; \$ \mathrm{P}<0 \cdot 001$.

Table 3 Estimates of prevelance rates (\%) of respiratory symptoms for overweight, average, and underweight 8 year old boys based on the age and sex adjusted model

\begin{tabular}{|c|c|c|c|c|c|c|}
\hline \multirow[t]{3}{*}{ Respiratory symptom } & \multicolumn{3}{|l|}{ England } & \multicolumn{3}{|l|}{ Scotland } \\
\hline & \multicolumn{3}{|c|}{ Weight for height SDS } & \multicolumn{3}{|c|}{ Weight for height SDS } \\
\hline & $\begin{array}{l}-1 \cdot 5 \\
\text { (underweight) }\end{array}$ & $\begin{array}{l}0 \\
\text { (average) }\end{array}$ & $\begin{array}{l}+1.5 \\
\text { (overweight) }\end{array}$ & $\begin{array}{l}-1 \cdot 5 \\
\text { (underweight) }\end{array}$ & $\begin{array}{l}0 \\
\text { (average) }\end{array}$ & $\begin{array}{l}+1.5 \\
\text { (overweight) }\end{array}$ \\
\hline Colds usually go to the chest & 23.9 & $27 \cdot 6$ & $33 \cdot 1$ & $26 \cdot 6$ & $28 \cdot 7$ & $34 \cdot 0$ \\
\hline Chest ever wheezy or whistling & 11.9 & $12 \cdot 4$ & $14 \cdot 4$ & $8 \cdot 1$ & $12 \cdot 4$ & $16 \cdot 4$ \\
\hline Bronchitis & $4 \cdot 2$ & $4 \cdot 6$ & $6 \cdot 1$ & $2 \cdot 8$ & $4 \cdot 1$ & $6 \cdot 7$ \\
\hline
\end{tabular}

however, was not always reached as in the pooled sample.

When the quadratic term for each obesity measure was included in the analyses for the age-sex model, it was not significant at the five per cent level, except for the weight for height quadratic term in relation to 'cough first thing in the morning' in Scotland. The weight for height quadratic term in England was borderline non-significant $(0.05<\mathrm{P}<0.1)$ for bronchitis, 'wheezy chest most days', and 'cough first thing in the morning'.

Table 3 gives the estimated prevalence rates as an illustration for boys aged 8 years who were overweight, average, and underweight, defined as having weight for height SDS $+1.5,0$, and -1.5 respectively. These were calculated from the regression coefficients for the age-sex model for the three respiratory symptoms which showed a consistent positive association with weight for height (the quadratic weight for height term was included in these calculations). The relative risk for overweight boys compared with those who were average or underweight varied from 1.2 to 1.5 in England and from 1.2 to 2.4 in Scotland. The number of children for the Scottish estimates, however, was about one third of that for the English and consequently the estimates were less precise. In contrast to these three symptoms, the lean boys (triceps skinfold SDS -1.5 ) had a high prevalence rate for 'day or night cough' with a risk relative to the obese of 1.7 at 8 years of age.

\section{Discussion}

The results indicate that primary school children who are fat (triceps skinfold) or overweight (weight for height) have a higher prevalence rate for bronchitis and for 'colds usually going to the chest'. Overweight children also have a higher prevalence of the symptom 'chest ever wheezy'. In contrast, lean English children have the greatest prevalence for the symptom 'usually coughs during the day or night'.

A significant negative association was not found between asthma and either of the obesity measures. Other work ${ }^{345}$ showed a lower mean weight for 
asthmatic children, however, these investigators found this effect chiefly in older children who had greater severity of asthma than those included in our study.

In population surveys the results can be influenced by incompleteness of data, confounding factors, and inaccurate or differential reporting of respiratory illness by parents. Analyses of English children, repeated with a reduced number of variables so that a larger sample was included than in the main analyses, did not alter the main results.

The results for the fully adjusted and the age-sex adjusted model were similar. The relation between overweight or fatness and respiratory symptoms is, therefore, only slightly affected by confounding factors associated with respiratory illness.

Parental reports of respiratory symptoms have been checked for accuracy in some studies with general practitioners' notes, with conflicting results. ${ }^{12} 1314$ The validity of parents' recall of respiratory symptoms, however, is supported by the consistency found between parental reporting of asthma, severe colds, chronic cough and bronchitis, and the ventilatory function of children. ${ }^{12} 1415$

Differential reporting between mothers because of protectiveness of some mothers cannot be ruled out and may explain why, contrary to expectations, children from small families have a higher prevalence of 'colds usually going to the chest' than those from larger families. The analysis, however, accounts for many factors likely to be linked to maternal protectiveness which might possibly have influenced the reporting of illness-ie one parent and small families and social class. Therefore, any confounding effect of differential maternal recall should have been accounted for unless mothers of obese children are per se more protective than other mothers. This suggestion has some support in the finding of higher than expected prevalence of obesity in the small group of children who weighed less than $2500 \mathrm{~g}$ at birth in small families. ${ }^{16}$

In two previous studies $^{12}$ clinical details of respiratory illness were obtained from the general practitioners or their records so that variation in maternal recall was not a problem, and it was shown that overweight infants had significantly more respiratory infections. Also, overweight infants aged under 1 year who were admitted to hospital for lower respiratory illness were found to require more bronchospasm relaxant treatment compared with those of normal body weight. ${ }^{117}$ Our study indicates that this association between overweight and respiratory illness does not resolve in childhood. Cross sectional analyses do not explain in which direction this causal relation lies; it seems, however, less plausible that the respiratory symptoms should cause obesity than that the obese children should have increased susceptibility to respiratory illness. Earlier prospective studies ${ }^{12}$ support this view.

Obesity is the most common nutritional disorder in childhood in the more highly developed countries. Around $10 \%$ and five per cent of primary school children are 10 to $20 \%$ and $21 \%$ or more above the average weight for height respectively. ${ }^{18}$ Respiratory illness is a major cause of childhood morbidity, it can be hypothesised that a reduction in respiratory illness can be made by preventing children becoming overweight. Nutrition health education relating to obesity might be more successful if the emphasis were on prevention of concurrent illness linked to obesity rather than a promise of health gains in later life.

We thank all doctors, teachers, administrators, nurses, and clerks in the study areas for their generous assistance, and the parents and children who participated; Professor W W Holland; and all our colleagues involved in the National Study of Health and Growth. This study is supported by a grant from the Department of Health and Social Security and Scottish Home and Health Department.

\section{References}

${ }^{1}$ Hutchinson-Smith B. The relationship between the weight of an infant and lower respiratory infection. Medical Officer 1970;123:257-62.

2 Tracey VV, De NC, Harper JR. Obesity and respiratory infection in infants and young children. Br Med J 1971;i:16-8.

${ }^{3}$ Peckham C, Butler N. A national study of asthma in childhood. J Epidemiol Community Health 1978;32:79-85.

${ }^{4}$ Hauspie RC, Gyenis G, Alexander F, Simon G, Susanne C, Madach A. Heights and weights of Hungarian and Belgian asthmatic boys. Hum Biol 1979;51:507-21.

${ }^{5} \mathrm{McNicol} \mathrm{KN}$, Williams HB. Spectrum of asthma in children-1. Clinical and physiological components. Br Med J 1973;iv:7-11.

${ }^{6}$ Douglas JWB, Blomfield JM. Children under five. London: George Allen and Unwin, 1958.

${ }^{7}$ Chamberlain RN, Simpson RN. The prevalence of illness in childhood. Bath: Pitman Medical, 1979.

8 Altman DG, Cook J. A nutritional surveillance study. Proc $R$ Soc Med 1973;66:646-7.

9 Rona RJ, Altman DG. National study of attained height, weight and triceps skinfold in English children 5 to 11 years old. Ann Hum Biol 1977;4:501-23.

${ }^{10}$ Chinn S, Morris RW. Standards of weight-for-height for English children from age 5.0 to 11.0 years. Ann Hum Biol 1980;7: 457-71.

11 Morris RW, Chinn S. Weight-for-height as a measure of obesity in English children five to 11 years old. Int $J$ Obes 1981; 5:359-66.

12 Watkins CJ, Burton P, Leeder S, Sittampalam Y, Weaver AMJ, Wiggins R. Doctor diagnosis and maternal recall of lower respiratory illness. Int J Epidemiol 1982;11:62-6.

${ }^{13}$ Colley JRT, Holland WW, Corkhill RT. Influence of passive smoking and parental phlegm on pneumonia and bronchitis in early childhood. Lancet 1974;ii:1031-4.

${ }^{14}$ Bland JM, Holland WW, Elliott A. The development of respiratory symptoms in a cohort of Kent school children. Bull Fur Physiopathol Respir 1974;10:699-716. 
${ }^{15}$ Colley JRT, Reid DD. Urban and social origins of childhood bronchitis in England and Wales. Br Med J 1970;ii:213-7.

16 Rona RJ, Chinn S. National study of health and growth: social and family factors and obesity in primary school children. Ann Hum Biol 1982;9:131-45.

17 Lazarev SG, Baranova EF. Clinical features of the course of pneumonia in children of the first year of life with excessive weight. Pediatriia 1979;4:15-7.

${ }^{18}$ Peckham CS, Stark O, Simonite V, Wolff O. Prevalence of obesity in British children born in 1946 and 1958. $\mathrm{Br} \mathrm{Med} \mathrm{J}$ 1983;286:1237-42.

Correspondence to Dr R J Rona, Department of Community Medicine, St Thomas's Hospital Medical School, London SE1 7EH.

Received 12 July 1984

The programme for the Annual Meeting contains abstracts for all the papers presented, including Plenary, Poster, and Group sessions. Copies of the programme are available at $£ 3$ from: The British Paediatric Association, 23 Queen Square, London WC1. 